Arhe XVI, 32/2019

UDK 1 Heisenberg W.

DOI https://doi.org/10.19090/arhe.2019.32.245-259

Originalni naučni rad

Original Scientific Article

\author{
ANJA CMILJANOVIĆ ${ }^{1}$ \\ Univerzitet u Novom Sadu, Filozofski fakultet
}

\title{
HAJZENBERGOV POJAM ZATVORENE TEORIJE I IDEJA NAUČNE REVOLUCIJE
}

Sažetak: U ovom radu nastojaćemo da istražimo Hajzenbergov pojam zatvorene teorije i njegovo razumevanje naučnih revolucija. Motiv za Hajzenbergovo bavljenje ovim idejama filozofije nauke leži u problemu datiranom početkom XX veka, osnivanjem kvantne teorije, kada su se fizičari našli u problemu kako da razumeju odnos između klasične fizike, stare kvantne teorije i nove matrične mehanike. Najpre ćemo ispitati samu definiciju pojma zatvorene teorije, nakon čega ćemo preći na analizu osnovnih karakteristika zatvorenih sistema - ograničenost, potpuna tačnost i konačnost. Nakon toga, tematizovaćemo odnos zatvorenih sistema i mogućnost naučnih revolucija, da bismo naposletku, imajući u vidu postignute rezultate, prodiskutovali o odnosu Hajzenberga i Tomasa Kuna, odnosno o sličnosti i razlikama njihovih pojmova zatvorenog sistema i naučne paradigme.

Ključne reči: zatvoren sistem, naučna revolucija, fenomeni, aksiomatizacija, paradigma

\section{UVOD}

Verner Hajzenberg [Werner Heisenberg] pored toga što je $u$ istoriji nauke poznat kao jedan od osnivača kvantne teorije, prvi koji je dao njenu formalizovanu, matematičku shemu, koja je danas poznata kao matrična mehanika, u svojim delima posvetio je iznenađujuće mnogo pažnje razmatranju osnovnih filozofskih ideja. ${ }^{2} \mathrm{~S}$ obzirom na to da je njegovo područje delovanja $u$ fizici prvenstveno kvantna fizika $i$

\footnotetext{
${ }^{1}$ E-mail adresa autorke: anja.cff@gmail.com

2 Zanimljivu studiju o razvoju Hajzenbergovih filozofskih ideja u vezi sa kvantnom teorijom dao je Heelan, Patrick. Observable: Heisenberg's Philosophy of Quantum Mechanics. New York: Peter Lang Publishing, Inc. 2016.
} 
subatomske čestice, jasno je da se u fokusu njegovih filozofskih razmatranja nalaze materijalističke teorije prirode, počevši od

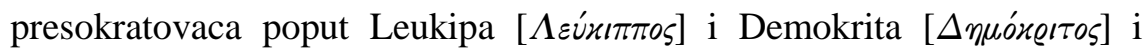
njihove atomistike, pa sve do novovekovnih materijalističkih teorija Dekarta [Descartes], Holbaha [Holbach] i Lametrija [La Mettrie]. ${ }^{3}$ Međutim, u njegovom opusu nalaze se i razmatranja o osnovnim problemima filozofije nauke, tačnije, o pojmu naučne teorije, njenom formiranju i načinima uz pomoć kojih dolazi do promene vladajućih naučnih paradigmi.

Ova činjenica ne iznenađuje mnogo, s obzirom na to da je jedno od važnijih pitanja Hajzenbergovog naučnog delanja u njegovoj ranoj fazi, posvećeno odnosu klasične fizike, stare kvantne teorije i nove matrične mehanike. Razumljivo je da ga je bavljenje tim pitanjem moralo dovesti do osnovnih pitanja filozofije nauke, pre svega, zato što se radi o tri teorije koje svaka za sebe zadovoljavajuće vrši funkciju opisa prirode u svom domenu, ali koje su međusobno protivrečne. Bez potrebe da u ovom radu ulazimo u dublje razmatranje problematike odnosa klasične fizike, stare kvantne teorije i nove matrične mehanike, važno je samo da istaknemo da kada je reč o odnosu te tri teorije, početkom i sredinom XX veka fizičari su bili podeljeni između dva osnovna stanovišta, gde jedni zastupaju ideju da te tri teorije nemaju zajedničkih tačaka, te da svaka od njih predstavlja neku vrstu promene naučne paradigme $u$ odnosu na prethodnu, dok druga grupa stoji na stanovištu mogućnosti uspostavljanja kontinuiteta između njih. Kontinuitet na koji se ovde misli nije klasično poimanje ideje kontinuiteta, kao kontinualnog razvoja jedne teorije iz druge, gde svaka sledeća sobom obuhvata prethodnu i širi njen objašnjavalčki domen, već se kontinuitet razumeva kao razvoj novih naučnih teorija, u kojima elementi prethodnih teorija ,preživljavaju“ ali na drugačiji način, odnosno u skladu sa parametrima koje je postavila nova naučna teorija.

Za nas je bilo važno da ovde pomenemo ovu problematiku, zato što smatramo da Hajzenbergovo bavljenje filozofijom nauke, problemima

\footnotetext{
${ }^{3}$ Up. Hajzenberg, Verner. Fizika i metafizika. Beograd: Nolit, 1972.
} 
statusa naučnih teorija i njihovih međusobnih odnosa, svoje korene vuče upravo iz problema razumevanja odnosa gore pomenute tri teorije.

\section{POJAM ZATVORENE TEORIJE}

No, kao što i sam naslov rada kaže, naša tema u ovom radu jeste Hajzenbergov pojam zatvorene teorije kao glavni pojam njegove uslovno rečeno „filozofije nauke“ u ranoj fazi Hajzenbergovog naučnog rada. Izvorno Hajzenberg ovaj pojam naziva abgeschlossene Theorie, gde bi ovo abgeshlossene značilo „zatvoreno“, „zaključano“, „izolovano“ ili pak „samodovoljno.“4 ${ }^{4}$ Hajzenberg na mnogo mesta u svojim radovima govori o pojmu zatvorene teorije, ređe dajući definiciju tog pojma, pokušavajući zapravo kroz davanje primera ,zatvorenih“ teorija da eksplicira sadržaj tog pojma. Mesto koje ćemo mi najviše u radu koristiti za istraživanje ovog njegovog pojma, ali ne i jedino, jeste deo njegove knjige Fizika $i$ filozofija, posvećen istraživanju međusobnih odnosa do sada formulisanih naučnih teorija.

Jedno od važnijih, ali i retkih mesta u toj knjizi, gde se može nazreti delimično jasna definicija pojma zatvorene teorije jeste deo kada Hajzenberg govori da zatvoren skup, ili neki zatvoren naučni sistem karakteriše grupa definicija i aksioma, koji su međusobno povezani; svaki pojam tog sistema može se predstaviti jednim matematičkim simbolom, a veze između različitih pojmova predstavljaju se matematičkim jednačinama koje su izrađene pomoću simbola. ${ }^{5}$ Hajzenberg je bio veliki pobornik apsolutne moguće aksiomatizacije i formalizacije naučnih teorija, što je samorazumljivo imajući u vidu da je upravo on ponudio matričnu mehaniku kao matematičku formulaciju stare kvantne teorije, stoga ne čudi da je mogućnost aksiomatizacije jedan od nužnih uslova $i$ glavnih zahteva koje određena teorija mora da ispuni da bi mogla da se okarakteriše kao zatvoren sistem. On smatra da pojmovi koji su stvoreni

${ }^{4}$ Bokulich, Alisa. Reexamining the Quantum - Classical Relation: Beyond Reductionism and Pluralism. Cambridge: Cambridge University Press, 2008. str. 31.

${ }^{5}$ Hajzenberg, Verner. Fizika i filozofija. Beograd: Umetničko društvo Gradac Čačak, 2000. str. 52. 
na osnovu iskustva, moraju uz pomoć definicija i aksioma biti usko određeni i fiksirani u svojim odnosima na takav način da svakom pojmu odgovara konkretan matematički simbol, te se na taj način može uspostaviti veza između empirijskog sveta i aksiomatskih sistema zatvorenih teorija. ${ }^{6}$

U tom trenutku kada Hajzenberg piše Fiziku i filozofiju, 1958. godine, on kao jedine zatvorene teorije vidi njutnovsku mehaniku, teoriju toplote, elektrodinamiku zajedno sa teorijom relativnosti, te kvantnu teoriju. $^{7}$ Pre nego što nastavimo dalje, ovde ćemo napraviti malu digresiju, postavljajući pitanje zašto je Hajzenberg izabrao baš te četiri teorije kao predstavnike zatvorenih naučnih sistema, kao i da li su to jedini mogući zatvoreni sistemi, odnosno da li ta četiri sistema obuhvataju kompletno polje fizike. Hajzenbergov odgovor na to pitanje prilično je jasan. Iz njegove perspektive, to su jedina četiri sistema koja su zatvorena, dok na primer, opšta teorija relativnosti predstavlja „otvorenu“ teoriju, jer još uvek nije dostigla konačan oblik. Pored nje, Hajzenberg takođe smatra da će peti skup tek biti otkriven, gde će prvi, treći i četvrti skup predstavljati granične slučajeve, a taj peti skup biće u vezi sa teorijom elementarnih čestica. ${ }^{8}$

\section{KRITERIJUMI ZA ODREĐIVANJE ZATVORENIH SISTEMA}

Vratimo se sada na sam pojam zatvorene teorije. Hajzenberg iznosi tri prilično smele tvrdnje o karakteristikama tih zatvorenih teorija. Prva je da je svaki zatvoren sistem ograničen na određeni domen prirodnih fenomena, druga da je njihov opis tih fenomena potpuno tačan, i na kraju, treća, da je svaki od tih opisa konačan, da je trajno dostignuće,

\footnotetext{
${ }^{6}$ Bokulich, Alisa. Reexamining the Quantum - Classical Relation: Beyond Reductionism and Pluralism.str. 32. Takođe, Up. Heisenberg, Werner. Physics and Beyond: Encounters and Conversations. New York: Harper \& Row, Publishers, 1971.

${ }^{7}$ Up. Hajzenberg, Verner. Fizika i filozofija. Beograd: Umetničko društvo Gradac Čačak, 2000. str. 57 - 58.

${ }^{8}$ Ibid.
} 
te se ne može menjati daljim razvojem nauke. ${ }^{9}$ Ove tvrdnje zaista jesu smele i podložne diskusiji iz više razloga. Najpre, Hajzenbergova tvrdnja da je svaki zatvoren sistem ograničen na određeni domen prirodnih fenomena u direktnoj je suprotnosti sa uvreženom idejom da kvantna teorija predstavlja univerzalnu naučnu teoriju koja adekvatno opisuje sve fenomene prirode. Hajzenberg, pak smatra, da je Njutnova mehanika, kao jedan od zatvorenih sistema, u svom domenu potpuno tačna i precizna, te bi svaki dalji pokušaj njenog unapređenja bio besmislen. ${ }^{10}$

Objašnjenje za ovakvu Hajzenbergovu tezu možemo potražiti u njegovoj ideji o primenljivosti fizičkih pojmova. Reč je o tome da je domen primenljivosti zatvorene naučne teorije određen mogućnošću primenljivosti osnovnih pojmova te teorije na objašnjenje datih fenomena. Sam proces aksiomatizacije naučne teorije nužno ograničava domen primene određenih pojmova. Na koji način je to moguće? Naime, Hajzenberg smatra da dokle god naše pojmove crpimo iz iskustva, oni su usko povezani sa prirodom, odnosno fenomenima koje opisuju. Međutim, kada započnemo proces aksiomatizacije sistema, ti pojmovi bivaju „odsečeni“ od iskustva. Oni i dalje ostaju prilagođeni širokom spektru fenomena, ali nikada se unapred ne može znati dokle pojmovi koji su određeni definicijama i odnosima unutar aksiomatskog sistema, mogu biti primenjivani u opisu prirode. ${ }^{11}$

Vidimo, dakle, da polje fenomena koji su obuhvaćeni određenim zatvorenim sistemom ne može biti određeno a priori, već da ograničenja dolaze iz samog iskustva, odnosno empirijskim putem. ${ }^{12}$ Ovo Hajzenbergovo objašnjenje može delovati prilično zbunjujuće, stoga ćemo pokušati da malo rasvetlimo šta on tačno podrazumeva pod tim da ograničenje dolazi iz samog iskustva. Naime, reč je tome da određeni naučni sistem mora moći da adekvatno opiše široko polje našeg iskustva.

9 Up. Heisenberg, Werner. Oral history interview of Werner Heisenberg by Thomas Kuhn. 27. II 1963. https://www.aip.org/history-programs/niels-bohrlibrary/oral-histories/4661-9 22.VIII 2019

${ }^{10}$ Ibid.

${ }^{11}$ Hajzenberg, Verner. Fizika i filozofija. str. 57.

12 Bokulich, Alisa. Reexamining the Quantum - Classical Relation: Beyond Reductionism and Pluralism. str. 32. 
To široko polje iskustva koje naučna teorija opisuje mora biti izraženo kroz matematičke jednačine, ukoliko govorimo o aksiomatizovanom sistemu. Stoga, ograničenja našeg iskustvenog polja koje možemo da opišemo ne mogu biti izvedena iz samih pojmova, koji su određeni spram odnosa i definicija iz aksiomatskog sistema u kojem su postavljeni. Konkretnije, pojmovi nisu jasno određeni spram prirode, već su definisani spram mogućih veza između pojmova. Na taj način, jedino ograničenje može dolaziti iz prirode, iz samog iskustva, tj. iz činjenice da pojmovi ne omogućavaju potpun opis posmatranih pojava. ${ }^{13}$ Primer kojim bismo mogli da ilustrujemo neadekvatnost određenih pojmova $u$ opisu posmatranih pojava jeste Ajnštajnovo otkriće specijalne teorije relativiteta. Pojmovi prostora i vremena definisani u aksiomatskom sistemu njutnovske mehanike prosto nisu mogli na adekvatan način da se primene na objašnjenje fenomena koji spadaju u domen specijalne teorije relativiteta.

Druga tvrdnja koju Hajzenberg iznosi, kao što smo već videli jeste ta da svaki zatvoren sistem potpuno tačno, odnosno adekvatno opisuje domene prirode koje obuhvata. Ova tvrdnja je problematična, i ovde ćemo se složiti sa Alisom Bokulić [Alisa Bokulich], koja smatra da su teorije sačinjenje od idealizacija, te da u najboljem slučaju mogu da obezbede modele fenomena, ali ne i njihov potpuno tačan opis. ${ }^{14}$ No, Hajzenberg smatra da gde god možemo primeniti pojmove klasične fizike, tu će njeni zakoni biti u potpunosti dokazani, te će na taj način potpuno tačno opisivati određene fenomene. Sa druge strane, Hajzenberg isto tako tvrdi da se pojmovi klasične fizike primenjuju tamo gde njeni zakoni u potpunosti funkcionišu. $\mathrm{Na}$ taj način, Hajzenberg zapada u svojevrsni circulus vitiosus, jer smatra da teorija adekvatno opisuje fenomene tamo gde mogu da se primene njeni pojmovi, a primena pojmova, pak zavisi od toga da li teorija na odgovarajući način opisuje te iste fenomene. Glavni problem ovde, složićemo se, jeste taj konkretan nedostatak kriterijuma na osnovu kojih Hajzenberg smatra da je moguće

\footnotetext{
${ }^{13}$ Hajzenberg, Verner. Fizika i filozofija. str. 58.

${ }^{14}$ Up. Bokulich, Alisa. Reexamining the Quantum - Classical Relation: Beyond Reductionism and Pluralism. str. 33.
} 
primenjivati pojmove jednog zatvorenog sistema. Taj problem, moramo priznati nije specifično vezan za Hajzenberga, već je reč o epistemološkom problemu koji se javlja u kvantnoj teoriji sa obzirom na neophodnost primene klasičnih pojmova na fenomene koji ni na koji način ne odgovaraju opisima klasične mehanike.

Treća, ne i manje važna tvrdnja koju Hajzenberg iznosi u vezi sa karakteristikama zatvorenih sistema jeste ona da je takav zatvoren sistem konačan, te da se dalje ne može modifikovati i usavršavati daljim napretkom nauke. ${ }^{15}$ Ova tvrdnja je iznenađujuća, pre svega, jer bi kvantna teorija kao takva, trebalo da u potpunosti zameni klasičnu mehaniku. Ovu tvrdnju bismo možda mogli razumeti, ukoliko tu "konačnost" nekog zatvorenog sistema razumevamo kao dovršenost $\mathrm{u}$ obliku jednog aksiomatskog sistema, gde se na osnovu malog broja definicija i aksioma, može objasniti veliki broj fenomena, te su isto tako, empirijski proverene i eksperimentalno dokazane. ${ }^{16} \mathrm{Na}$ taj način bi, na primer, klasična mehanika zaista bila jedan konačan zatvoren sistem, koji bi potpuno tačno opisivao fenomene sa područja klasične mehanike. Međutim, kao i sa prethodnom tvrdnjom, ostaje kao nerešeno pitanje šta je konkretno područje klasične mehanike, odnosno gde se tačno prostire njen domen.

Do sada smo videli osnovne definicije Hajzenbergovog pojma zatvorene teorije i neke njene ključne karakteristike, te ćemo sada preći na razmatranje međusobnih odnosa tih zatvorenih teorija, kao i na koji način mogu korespondirati zatvorene teorije sa idejom naučnih revolucija. S obzirom da je evidentan napredak nauke i otkrivanje novih naučnih teorija, za Hajzenberga mora biti nužno da pronađe način na koji ti zatvoreni sistemi mogu biti zamenjeni novim naučnim teorijama koje pretenduju na objašnjavanje istih domena prirodnih fenomena.

\footnotetext{
${ }^{15}$ Hajzenberg, Verner. Fizika i filozofija. str. 54.

16 Heisenberg, Werner. "The Correctness-Criteria for Closed Theories in Physics." U Encounters with Einstein: And Other Essays on People, Places, and Particles. Princeton: Princeton University Press, 1983. str. 172.
} 


\section{ZATVORENI SISTEMI I NAUČNE REVOLUCIJE}

U svojoj knjizi Preispitivanje klasično-kvantne relacije (Reexamining the Quantum-Classical Relation), Alisa Bokulić Hajzenbergove ideje o zatvorenim sistemima naziva holističkim. ${ }^{17}$ Ovaj zaključak Bokulić izvodi na osnovu Hajzenbergove teze da svaki zatvoren sistem u sebi sadrži takvu međusobnu povezanost elemenata i pojmova, da je nemoguće promeniti jedan, a da se time ne promene $\mathrm{i}$ ostali. Holističko razumevanje međusobnih odnosa pojmova $u$ zatvorenom sistemu svakako može biti odgovarajuće tumačenje Hajzenbergovih ideja o zatvorenim sistema. On na više mesta govori o tome, ali ćemo ovom prilikom izdvojiti jedno na kom se najjasnije može videti na šta zapravo Hajzenberg cilja:

„Već je rečeno da se pojmovi prirodnih nauka ponekad mogu jasno odrediti na osnovu njihove međusobne povezanosti. Ova mogućnost po prvi put je ostvarena u Njutnovom delu Principia i upravo iz tog razloga Njutnovo delo je imalo ogroman uticaj na ukupan razvoj prirodnih nauka u narednim vekovima. Njutn svoje delo Principia započinje grupom definicija i aksioma koji su međusobno povezani tako da čine ono što se može nazvati 'zatvoren sistem'....Povezanost različitih pojmova u sistemu toliko je bliska da, uopšteno gledano, nije moguće promeniti nijedan od pojmova, a da se pri tom ne razori čitav sistem. “18

Dakle, ne samo da su već formirani pojmovi međusobno povezani, nego i njihov sadržaj i smisao u sistemu određeni su u relaciji spram drugih pojmova. $\mathrm{Na}$ taj način nije moguće vršiti nikakve modifikacije samog sistema, a da se ne uništi ceo sistem. Ova karakteristika zatvorenog sistema potiče iz njegove aksiomatske formulacije, jer kada se pojmovi nalaze u sklopu jednog askiomatskog sistema, njihovo značenje više ne može biti formirano samostalno, već uvek u vezi sa drugim pojmovima tog sistema. Jedan od boljih primera za

${ }^{17}$ Bokulich, Alisa. Reexamining the Quantum - Classical Relation: Beyond Reductionism and Pluralism. str. 35.

${ }^{18}$ Hajzenberg, Verner. Fizika i filozofija.str. 52 
ovo o čemu govorimo jeste klasični pojam sile, u Njutnovom sistemu sveta, gde se on ne može definisati bez isto tako klasičnih pojmova mase i ubrzanja.

Sada se postavlja pitanje na koji onda način može doći do promene samih sistema, kako se oni smenjuju, odnosno kako dolazi do naučnih revolucija, imajući u vidu sve navedene karakteristike zatvorenih sistema. Odgovore na ova pitanja Hajzenberg pokušava da da u intervjuu koji je sa njim u više sesija radio Tomas Kun [Thomas Kuhn] u zimu 1962. i početkom 1963. godine na institutu Maks Plank u Minhenu. U tom intervjuu, konkretno u sesiji XI, održanoj 27. II 1963. godine, Hajzenberg tvrdi da kada dođe do otkrića novog fenomena, on ne može biti objašnjen prostom modifikacijom postojećeg zatvorenog sistema. ${ }^{19}$ Naprotiv, prelazak iz jednog zatvorenog sistema u novo iskustveno polje zahteva jedan intelektualni skok, i ne može se postići pukim proširivanjem već postojećeg znanja:

„...u nauci, prelazak iz prethodno istraživanog polja iskustva u neko novo, nikada se neće sastojati prostom primenom već poznatih zakona na novo polje. Naprotiv, zaista novo polje iskustva uvek će voditi do kristalizacije novog sistema naučnih zakona" ${ }^{20}$

Dakle, svako novo polje iskustva zahteva formiranje novog zatvorenog sistema. Ne može biti reči o kontinualnoj promeni, već to formiranje novih sistema mora biti uslovno rečeno "odjednom", odnosno mora se dogoditi neki vid naučne revolucije. Kod Hajzenberga ne može biti reči o jednom kontinuiranom razvoju nauke, jer bi to po njemu bio

${ }^{19}$ Up. Heisenberg, Werner. Oral history interview of Werner Heisenberg by Thomas Kuhn. 27. II 1963.

20 "the transition in science from previously investigated fields of experience to new ones will never consist simply of the application of already known laws to these new fields. On the contrary, a really new field of experience will always lead to the crystallization of a new system of scientific concepts and laws. [prevod A. C.]" Heisenberg, Werner. "Recent Changes in the Foundations of Exact Science." U Philosophical Problems of Quantum Physics. Woodbridge: Ox Bow Press, 1979. str. 24. Takođe, Up. Heisenberg, Werner. "Nobel Lecture: The Development of Quantum Mechanics." U: Nobel Lectures, Physics1922 1941. Amsterdam: Elsevier Publishing Company, 1965. 
jedan besmislen i beskonačan proces, već je ono što daje naučnost samoj nauci upravo njena mogućnost formiranja zatvorenih aksiomatskih sistema koji na potpun i legitiman način opisuju određene fenomene u prirodi.

\section{HAJZENBERG I KUN}

U ovakvom Hajzenbergovom razumevanju teorije promene i ideje naučne revolucije možemo uočiti sličnosti sa idejama Tomasa Kuna, pre svega sa njegovim pojmovima naučne paradigme, ali i naučne revolucije takođe. Bokulić u jednom članku lepo primećuje da su u već pomenutom intervjuu, Hajzenberg i Kun bili svesni sličnosti njihovih ideja u oblasti filozofije nauke. ${ }^{21}$ Naime, Hajzenberg je pre intervjua imao priliku da čita Kunovu knjigu Struktura naučnih revolucija (The Structure of Scientific Revolution), te u intervjuu saopštava Kunu da je bio veoma zadovoljan načinom na koji Kun koristi pojam paradigme, kao i da su prekidi u vidu naučnih revolucija nužni, odnosno da je nužno, da kada dođemo do nekog novog polja iskustva, presečemo "granu" na kojoj sedimo (cut the branch on which one is sitting), te da formiramo nove naučne sisteme i formulišemo nove zakone koji će biti adekvatni za te fenomene. ${ }^{22}$

Moramo ukratko videti šta podrazumevaju Kunovi pojmovi paradigme i naučne revolucije, odnosno kakav je tačno njihov odnos, da bismo razumeli o kakvoj se sličnosti radi između Hajzenberga i Kuna. Naime, Kunov pojam paradigme, kao što smo već rekli, sličan je Hajzenbergovom pojmu zatvorenog sistema. Paradigma predstavlja skup trenutno vladajućih naučnih teorija, prihvaćenih od strane naučne zajednice, koje na adekvatan način opisuju fenomene kojima se bave. ${ }^{23}$ Osnovne vrednosti koje ta paradigma mora da ima jesu tačnost,

${ }^{21}$ Up. Bokulich, Alisa. „Open or Closed? Dirac, Heisenberg and the Relation between Classical and Quantum Mechanics.“ Studies in History and Philosophy of Modern Physics 35 (2004): 377 - 396. str. 388.

${ }^{22}$ Up. Heisenberg, Werner. Oral history interview of Werner Heisenberg by Thomas Kuhn. 27. II 1963.

${ }^{23}$ Up. Kun, Tomas. Struktura naučnih revolucija. Beograd: Nolit, 1974. 
konzistentnost, širina (da obuhvati što više fenomena), jednostavnost i plodnost. Period vladanja jedne paradigme Kun naziva periodom normalne nauke, u kojem se odvija razrađivanje te paradigme, $\mathrm{i}$ uspostavljaju orijentiri za dalja eksperimentalna istraživanja.

No, Kun isto tako smatra da je naučna revolucija po sebi nužna, odnosno da u nekom trenutku mora doći do smene vladajuće paradigme $\mathrm{i}$ njene zamene. ${ }^{24}$ Primer za to je Njutnova mehanika, kao prva uspostavljena paradigma u naučnom svetu, smenjena je pojavom Ajnštajnove specijalne teorije relativnosti. Kada se pojavi nova paradigma, ona mora da obuhvati iste fenomene kao i stara, ali i da obuhvati nove, koji su ostali izvan objašnjenja prethodno vladajuće paradigme.

Vidimo, dakle, da svakako postoje određene sličnosti izmedju Hajzenbergovog pojma zatvorene teorije i Kunovog pojma paradigme i naučne revolucije. Međutim, to nisu jedine sličnosti između naučnika i filozofa. Hajzenberg se, pored toga što podržava Kunov pojam paradigme, slaže i sa Kunovom tezom o nesamerljivosti (incommensurability). $\mathrm{O}$ čemu je reč? Kun smatra da paradigma kao takva predstavlja način na koji razumevamo prirodu. Paradigme se međusobno ne razlikuju samo po slici prirode koju pružaju, već i po metodi koju koriste, problemima koje ističu i rešenjima koje uz to pružaju. Samim tim, kada dođe do smene paradigme i uspostavljanja nove vladajuće paradigme, ne samo da dolazi do proširivanja, odnosno objašnjenja fenomena koji prethodnom paradigmom nisu bili obuhvaćeni, već se menja i naše razumevanje prirode, i što je važno uspostavljaju se novi odnosi među postojećim pojmovima i definicijama. Sa novom paradigmom, stari pojmovi, koncepti i eksperimenti uspostavljaju nove odnose, te da bi se na primer prešlo sa Njutnovog sistema sveta na Ajnštajnov, potrebno je uspostaviti nove odnose između na primer, pojmova prostora i vremena, koji su u Njutnovom sistemu bili nezavisni jedan od drugog, dok su kod Ajnštajna u neraskidivoj vezi. ${ }^{25}$

\footnotetext{
${ }^{24}$ Ibid.

${ }^{25}$ Up. Kun, Tomas. Struktura naučnih revolucija. Beograd: Nolit, 1974.
} 
U pomenutom intervjuu Hajzenberg ne samo da se slaže sa ovom Kunovom idejom, nego biva još rigorozniji u odnosu na Kuna, te smatra da je neophodno potpuno odbaciti stare pojmove, odnosno da su pojmovi korišteni $\mathrm{u}$ jednom zatvorenom sistemu neupotrebljivi $\mathrm{u}$ formiranju novog zatvorenog sistema. Za razumevanje novih fenomena, potrebni su novi pojmovi koji su tim fenomenima prilagođeni, i koji će u novom zatvorenom sistemu biti međusobno povezani. On koristi isti primer kao i Kun, primer Njutnovog poimanja prostora i vremena, i ono kako su oni razumljeni u Ajnštajnovom sistemu sveta. ${ }^{26}$ Dakle, sve i da pojmovi ostanu isti u dva različita zatvorena sistema, poput prostora $\mathrm{i}$ vremena kod Njutna i Ajnštajna, njihov sadržaj i značenje biće fundamentalno drugačiji. Stoga je neophodno da svaki zatvoren sistem ima svoj sistem pojmova, koji su na poseban način povezani, kako međusobno, tako i sa iskustvom, te ni na koji način ne mogu biti samostalno ubačeni $u$ drugačiji kontekst nekog drugog zatvorenog sistema.

No, pored navedenih sličnosti, između Hajzenberga i Kuna postoje svakako i razlike koje je neophodno pomenuti, ukoliko govorimo o njihovom odnosu. Za početak, Hajzenberg, kao što smo već videli smatra da su određeni zatvoreni sistemi konačni i trajni, te uvek istiniti u svom domenu. Kun, pak, sa druge strane, pre stoji na stanovištu da naučna revolucija i formiranje nove naučne teorije, pod novom paradigmom, radije predstavlja zamenu za trenutno postojeće teorije. U tom smislu, za Kuna bi kvantna teorija bila zamena za Njutnovu mehaniku, kao što je Njutnova mehanika predstavljala zamenu za Ptolomejev i Aristotelov sistem sveta. ${ }^{27} \mathrm{U}$ periodu normalne nauke, odvijaju se kontinuirana istraživanja, u kvantitativnom smislu, ne kvalititativnom, odnosno ne traže se kvalitativno drugačiji pristupi prirodi, već se usavršavaju postojeće teorije, reč je o jednom kontinuiranom rastu, koji se prekida momentom diskontinuiteta u vidu naučne revolucije.

${ }^{26}$ Up. Heisenberg, Werner. Oral history interview of Werner Heisenberg by Thomas Kuhn. 27. II 1963.

27 Up. Heisenberg, Werner. Oral history interview of Werner Heisenberg by Thomas Kuhn. 27. II 1963. 
Kod Hajzenberga, s druge strane, pored toga što on Ptolomejev sistem sveta ne posmatra kao zatvoren sistem, ne može biti reči o tome da nova teorija kao novi zatvoren sistem, zamenjuje staru. Ovo je razumljivo, ukoliko imamo u vidu ono što smo već govorili, da kao jednu od glavnih karakteristika zatvorenih sistema, Hajzenberg navodi njihovu konačnost i potpunu tačnost, odbacujući viđenje naučnih teorija kao aproksimativnih opisa prirodnih fenomena. U tom slučaju Njutnova mehanika ni na koji način ne može biti usavršena ili unapređena, ona je kao zatvoren sistem potpuno adekvatna za domen klasične mehanike. Iako je jasno i evidentno da je upravo kvantna teorija, odnosno mehanika usavršavanje stare Njutnove mehanike, Hajzenberg odbacuje to stanovište o usavršavanju klasične mehanike, tvrdeći da kvantna teorije nije usavršavanje, već zapravo radikalna rekonstrukcija i formiranje novog zatvorenog sistema sa drugačijim područjem delovanja.

Iz te perspektive možemo zaključiti da Hajzenberg stoji na stanovištu svojevrsnog teorijskog pluralizma. ${ }^{28}$ Kunovo učenje bi, pak, predstavljalo ideju o univerzalnosti, odnosno totalnosti vladajuće paradigme u određenoj nauci, $u$ onom smislu da kada dođe do naučne revolucije, i promene neke naučne paradigme, te nove teorije u sebi obuhvataju objašnjenja određenih fenomena iz prethodnih teorija, ali u sebe uključuju i nove, do sada neobjašnjene fenomene, zbog kojih je i došlo do promene paradigme.

Za Hajzenberga možemo reći da njegovo stanovište predstavlja teorijski pluralizam u onom smislu da on polje nauke vidi kao polje $u$ kojem postoji mnogo zatvorenih naučnih sistema, kao potpuno dovršenih celina, gde svaki od tih sistema važi u domenu u kojem se nalaze fenomeni kojima se taj sistem bavi. Nažalost, ovakvim svojim stanovištem, Hajzenberg ne ostavlja mnogo prostora za međuteorijske relacije, pogotovo za razvijanje odnosa između klasične mehanike i kvantne teorije. Prostor za razvijanje tog odnosa ne postoji onda kada Hajzenberg govori o teorijskim postavkama filozofije nauke. U trenutku kada se vrati u svoju ulogu fizičara, pogotovo u periodu kada je formirao

${ }^{28}$ Bokulich, Alisa. „Open or Closed? Dirac, Heisenberg and the Relation between Classical and Quantum Mechanics." str. 7. 
novu matričnu mehaniku, Hajzenberg na znatno drugačiji način govori o odnosu klasične i kvantne teorije, smatrajući svoju matričnu mehaniku i relacije neodređenosti kao krajnju formalizaciju Borovog principa korespondencije, čime se suštinski uspostavlja kontinuitet između klasične mehanike, stare kvantne teorije i nove matrične mehanike, te više ni na koji način ne može biti reči o zatvorenim naučnim sistemima.

\section{LITERATURA}

Bokulich, Alisa. „Open or Closed? Dirac, Heisenberg and the Relation between Classical and Quantum Mechanics." Studies in History and Philosophy of Modern Physics 35 (2004): 377 - 396.

Bokulich, Alisa. Reexamining the Quantum - Classical Relation: Beyond Reductionism and Pluralism. Cambridge: Cambridge University Press, 2008.

Hajzenberg, Verner. Fizika i filozofija. Beograd: Umetničko društvo Gradac Čačak, 2000.

Hajzenberg, Verner. Fizika i metafizika. Beograd: Nolit, 1972.

Heelan, Patrick. Observable: Heisenberg's Philosophy of Quantum Mechanics. New York: Peter Lang Publishing, Inc. 2016.

Heisenberg, Werner. "Nobel Lecture: The development of Quantum Mechanics." U: Nobel Lectures, Physics 1922 - 1941. Amsterdam: Elsevier Publishing Company, 1965.

Heisenberg, Werner. "Recent Changes in the Foundations of Exact Science." U Philosophical Problems of Quantum Physics. Woodbridge: Ox Bow Press, 1979.

Heisenberg, Werner. "The Correctness-Criteria for Closed Theories in Physics." U Encounters with Einstein: And Other Essays on People, Places, and Particles. Princeton: Princeton University Press, 1983.

Heisenberg, Werner. Oral history interview of Werner Heisenberg by Thomas Kuhn. 27. II 1963. https://www.aip.org/history-programs/niels-bohrlibrary/oral-histories/4661-9 22.VIII 2019

Heisenberg, Werner. Physics and Beyond: Encounters and Conversations. New York: Harper \& Row, Publishers, 1971.

Kun, Tomas. Struktura naučnih revolucija. Beograd: Nolit, 1974. 


\author{
ANJA CMILJANOVIĆ \\ University of Novi Sad, Faculty of Philosophy
}

\title{
HEISENBERG'S CONCEPT OF CLOSED THEORY AND IDEA OF SCIENTIFIC REVOLUTION
}

\begin{abstract}
In this paper, we will attempt to explore Heisenberg's concept of closed theory and his understanding of scientific revolutions. The motive for Heisenberg's pursuit of these ideas of philosophy of science lies in the problem dating back to the early twentieth century, the founding of quantum theory, when physicists found themselves in the problem of understanding the relationship between classical physics, the old quantum theory and the new matrix mechanics. First, we will examine the definition of the concept of closed theory, after which we will move on to the analysis of the basic characteristics of closed systems - boundedness, complete accuracy and finality. Hereafter, we will discuss the relationship between closed systems and the possibility of scientific revolutions, and finally, considering the results achieved, discuss the relationship between Heisenberg and Thomas Kuhn, that is, the similarities and differences of their concepts of closed systems and the scientific paradigm.
\end{abstract}

Keywords: closed theory, scientific revolution, phenomena, axiomatization, paradigm

Primljeno: 26.8.2019.

Prihvaćeno: 2.11.2019. 